\title{
Cortes Constitucionais em regimes autoritários e em democracias: controle ou instrumentalização do poder?
}

\author{
Constitutional Courts in authoritarian regimes and democracies: control or \\ instrumentalization of power?
}

Fabrício Castagna Lunardi*

\section{Resumo}

O presente artigo tem o objetivo de investigar como Cortes Constitucionais atuam em democracias e em regimes autoritários, bem como se esses regimes podem, na prática, se utilizar das Cortes para atingirem os seus objetivos ilegítimos, através de mecanismos de controle, ataques e retaliações. Também se busca analisar quais são os custos políticos assumidos pelos Tribunais Constitucionais na revisão judicial e na limitação dos poderes do governo central e de elites políticas, e como têm atuado para implementar ou melhorar as instituições democráticas. A pesquisa se desenvolve em uma linha crítico-metodológica, a partir de uma perspectiva comparada, e com amparo em teorias políticas que analisam os problemas do ponto de vista político-institucional. Ao final, conclui-se que, em algumas situações, Cortes Constitucionais foram subservientes e utilizadas para darem uma feição de legitimidade ao regime; em outras, assumiram um papel importante na redemocratização, bem como se opuseram a elites políticas. Além disso, o risco de descumprimento e de retaliações comumente são levados em consideração pelos membros da Corte, o que acaba moldando um padrão de comportamento que se direciona bastante para a prudência quando a questão afeta interesses de elites políticas ou do governo central.

Palavras-chave: Cortes constitucionais. Democracias. Regimes autoritários. Elites políticas. Governo.

\section{Abstract}

This paper aims to investigate how Constitutional Courts act in democracies and authoritarian regimes, as well as whether these regimes can, in practice, use the Cortes to achieve their illegitimate objectives through control mechanisms, attacks and retaliations. It also seeks to analyze what are the political costs incurred by the Constitutional Courts in judicial review and limitation of the powers of central government and political elites, and how they have acted to implement or improve democratic institutions. The research develops from a critical-methodological line, from a comparative perspective and supported by political theories that analyze the problems from the political-institutional point of view. In the end, it is concluded that, in some situations, Constitutional Courts were subservient and used to give the regime a legitimacy feature; in others, they took an important role in redemocratization, as well as opposed political elites. In addition, the risk of noncompliance and retaliation is commonly taken into account by members of the Court, which ultimately shapes a pattern of behavior that is highly prudent when it comes to the interests of political elites or central government.

Keywords: Constitutional Courts. Democracies. Authoritarian regimes. Political elites. Government.

\section{Introdução}

Há diversos juristas e, sobretudo, constitucionalistas que afirmam que as Cortes Constitucionais estariam se se imiscuindo nas funções do Legislativo ou do Executivo, que haveria uma "ditadura do Judiciário". ${ }^{1}$ No Brasil, fala-se, inclusive, numa "supremocracia". ${ }^{2}$ Pesquisadores que desenvolvem estudos sob o ponto de vista da teoria da legislação costumam defender que o Legislativo seria o órgão mais adequado para tomar decisões sobre direitos, bem como que o Judiciário deveria adotar uma postura de autocontenção em relação ao Parlamento.

\footnotetext{
Doutor e Mestre em Direito pela Universidade de Brasília (UnB). Professor da Escola Nacional de Formação e Aperfeiçoamento de Magistrados (ENFAM), da Escola de Formação Judiciária do TJDFT e da Pós-Graduação do Instituto Brasiliense de Direito Público (IDP). Coordenador do Projeto de Pesquisa "Direito e Política: riscos e desafios para o sistema de justiça brasileiro", EFJ/TJDFT. Juiz de Direito do TJDFT. Brasília - DF - Brasil. E-mail: fabricioclunardi@yahoo.com.br.

Nesse sentido, por exemplo: Delmanto (2018)

2 Essa tese foi defendida principalmente por Oscar Vilhena (2008, p. 59-60).
} 
Embora essas teses não sejam incorretas, cotejando essas afirmações com os estudos recentes de direito constitucional comparado, parece que os membros dos demais Poderes Constituídos não estão tão preocupados com essas questões. Pelo contrário, em alguns casos, aparentemente, o Executivo e o Legislativo não só toleram, como também fomentam a revisão judicial. Aliás, o que se observa é um aumento das funções e dos poderes das Cortes Constitucionais tanto em regimes democráticos como em regimes autoritários. Análises comparativas sobre a sua atuação em questões de interesse de elites políticas talvez mostrem que as Cortes Constitucionais são bem mais frágeis do que as teorias de ativismo judicial e as teorias da legislação costumam apresentar, e bem mais estratégicas e políticas do que as teorias jurídicoconstitucionais podem mostrar.

Assim, a presente pesquisa se torna importante visto que, embora vários autores já tenham desenvolvido diversas teorias sobre a expansão da revisão judicial ou sobre a necessidade de sua autocontenção, há carência de uma investigação crítico-reflexiva, teórica, comparativa e empírica sobre o papel desempenhado pelos Tribunais Constitucionais em regimes democráticos e regimes autoritários.

Nesse ínterim, o presente artigo pretende investigar quais as funções que as Cortes Constitucionais exercem, como é a sua efetiva atuação em democracias e em regimes autoritários, e como esses regimes podem, na prática, se utilizar das Cortes para atingirem os seus objetivos, através de mecanismos de controle, ataques e retaliações, geralmente sob uma máscara de legitimidade. Além disso, também se busca analisar quais são os custos políticos assumidos pelos Tribunais Constitucionais na revisão judicial e na limitação dos poderes do governo central e de elites políticas, quão estáveis são os tribunais para atuarem como guardiões da constituição e da democracia ao longo do tempo, e como tem sido, na prática, a atuação das Cortes Constitucionais na melhoria das condições democráticas.

A fim de atingir os seus objetivos, este artigo se desenvolve com base na opção de uma linha críticometodológica, com amparo nas teorias políticas, para além de questões puramente normativas, pretendendose investigar os problemas propostos, sobretudo, do ponto de vista político-institucional, considerando a atuação das Cortes Constitucionais em regimes democráticos e em regimes autoritários, em perspectiva comparada.

Para tanto, é imprescindível, inicialmente, investigar quais são os papeis que podem ser desempenhados pelas Cortes Constitucionais e como se dá a sua efetiva atuação em regimes autoritários e em democracias. A seguir, realiza-se uma análise comparativa da jurisdição constitucional em regimes democráticos e autoritários, considerando-se a atuação de Tribunais Constitucionais de diversos países, observando-se as razões da expansão dos seus poderes e da sua atuação, a sua relação com o governo e as elites políticos, os ataques sofridos, bem como o permanente risco de captura.

\section{A função e a efetiva atuação das Cortes Constitucionais em regimes autoritários e em democracias}

Diversos são os estudos que apontam que Cortes Constitucionais, na grande maioria das vezes, contribuíram para a consolidação e o desenvolvimento de regimes democráticos. Entretanto, com base nessa premissa, não se pode recair na falácia de que Cortes Constitucionais são sempre simpatizantes de regimes democráticos ou que sempre atuam em direção à democracia. Pelo contrário, há diversos casos em que Cortes Constitucionais são utilizadas por regimes autoritários para manterem o regime.

A interação entre o comportamento judicial e, em reação, o comportamento dos atores políticos é fundamental para explicar a expansão e o papel dos Tribunais Constitucionais nos diversos países, ${ }^{3}$ seja em regimes democráticos, seja autoritários. Analisando-se o comportamento dos juízes constitucionais na sua inter-relação com o presidente, políticos, parlamentares, grupos de interesse, entre outros atores, é

\footnotetext{
A esse respeito, Ran Hirschl (2006, p. 743-744), com base em estudos comparativos em relação à judicialização da política nos diversos países, mostra que um arcabouço constitucional favorável ao ativismo judicial, juízes "sedentos de poder" ou Cortes Constitucionais não deferentes não são condições suficientes para a judicialização da megapolítica ou da política pura. A judicialização da política nos diversos países não teria ocorrido sem o apoio, ao menos tácito, dos atores políticos.
} 
possível notar como a independência judicial e o nível de poder das Cortes podem ser aumentados, mantidos ou reduzidos conforme o comportamento dos diversos atores em diferentes contextos. ${ }^{4}$ Aliás, o nível de judicialização e o grau de intervenção do Judiciário na política dependem muito do tipo e da intensidade da relação entre juízes constitucionais e elites políticas. ${ }^{5}$

A partir de estudos comparados, Tom Ginsburg (2012, p. 739) identifica quatro tipos de papéis que os Tribunais Constitucionais podem desempenhar em transições democráticas: a) como agentes do passado, policiando a transição ou, até mesmo, preservando políticas do regime autoritário; b) como agentes do futuro, ajudando a transformar o processo político e estimulando a consolidação da democracia; c) em raras situações, desencadeiam o próprio processo de democratização, incentivando a mobilização e a transformação para o regime democrático, moldando estruturas e ambientes institucionais subsequentes; e d) serem simplesmente atores marginais, que não facilitam nem impedem uma transição para a democracia.

De outro lado, também não se pode dizer que regimes autoritários não têm interesse em implementar Tribunais Constitucionais. Com efeito, na prática, a maioria dos países com regimes autoritários possuem uma Constituição e um Tribunal Constitucional. Atualmente, por regimes autoritários deve-se entender não somente aqueles em que há ditaduras, mas também aqueles em que existe um "autoritarismo competitivo", como apontam Steven Levitsky e Lucan Way (2002, p. 52), ou seja, regimes em que "as instituições democráticas formais são amplamente vistas como o principal meio de obter e exercer autoridade política", e nos quais "os governantes violam essas regras com tanta frequência e de tal forma que o regime não cumpre os padrões mínimos para a democracia".

Hodiernamente, o que caracteriza um regime como autoritário não é a ausência de constitucionalismo ou de um Tribunal Constitucional, mas a forma como as suas instituições trabalham. Nesse ponto, vale aqui uma questão levantada por Mark Tushnet (2015, p. 421) ao analisar regimes autoritários e regimes híbridos: se o constitucionalismo implica limitações ao governo e os regimes autoritários são aqueles em que o governo é ilimitado, por que esses regimes sempre possuem constituições?

Em primeiro lugar, as constituições podem ser utilizadas instrumentalmente em regimes autoritários para que os seus líderes possam se perpetuar no poder. Como mostram Alberto Simpser e Tom Ginsburg (2014), em regimes autoritários, a constituição serve como uma espécie de manual de operação, para que sejam seguidas as instituições do regime; como outdoors, com propagandas do regime, e como vitrines para aqueles que observam o país de fora do regime, a fim de que possam conhecê-lo da forma que os governantes pretendem.

Ao investigar o que motiva líderes de governos autoritários a estabelecer instituições judiciais com diferentes graus de autonomia, Tamir Moustafa e Tom Ginsburg (2008) identificam cinco funções primárias dos tribunais em Estados autoritários, concluindo que eles podem ser usados para: a) estabelecer o controle social e o controle de adversários políticos; b) reforçar a existência de um regime com legitimidade "jurídica"; c) fortalecer a ideia de cumprimento de normas administrativas dentro do mecanismo burocrático do Estado e resolver problemas de coordenação entre facções dentro do mesmo regime; d) facilitar o comércio e o investimento; e e) implementar políticas controversas de modo a manter a política distante dos elementos centrais do regime.

A Rússia é um bom exemplo disso. Vladimir Putin (no poder desde 1999) se utilizou da revisão judicial para ajudar a consolidar seu poder. A fim de criar um espaço político unificado, ele autorizou tribunais federais a anular leis regionais inconsistentes com a Constituição. Essa autorização, em uma análise superficial, poderia ser entendida como sendo apenas uma disposição neutra acerca do federalismo, de modo que, a uma primeira vista, seria consistente com outros Estados que adotam sistemas federalistas, como EUA

\footnotetext{
$4 \quad$ "Institutional analysis can only take us so far in understanding judicial independence. At both state and federal levels, important elements of independence are functions of the behaviors of judges, voters, interest groups, members of the Congress, and the president. Viewed in this light, judicial independence is maintained or eroded as much by choices and behaviors as by institutions and laws. We should work to improve our understanding of these behavioral factors in judicial independence" (FRANKLIN, 2002, p. 158).

5 No mesmo sentido: Sweet (2000, p. 196).
} 
e Brasil. Todavia, na Rússia, essa disposição foi utilizada por Putin para concentrar cada vez mais poder. A esse respeito, Ozan Varol (2015, p. 1689) aponta que, no discurso de Putin, a nova autoridade judicial federal, para derrubar as leis regionais, apenas enfatizava o "compromisso da Rússia com a legalidade e o Estado".

Ozan Varol também mostra que os tribunais federais russos desempenharam o seu novo poder com zelo e derrubaram milhares de leis regionais, o que permitiu que Putin centralizasse e consolidasse seu poder, bem como reduzisse os controles verticais por governos regionais. ${ }^{6}$

A concentração de poder não é a única "utilidade" de Cortes Constitucionais para regimes autoritários. Em tais regimes, os Tribunais Constitucionais também podem servir como instrumentos para que governos atraiam investimentos estrangeiros. Aliás, diversas instituições financeiras internacionais e os governos de diversos países, através de financiamentos e doações, ajudaram, direta ou indiretamente, a promover reformas judiciais e a fortalecer o Estado de direito (SANTISO, 2005, p. 117).

Com efeito, os investidores precisam da segurança proporcionada por um órgão estatal imparcial que Ihes garanta algum sucesso em eventuais demandas contra o Estado, ou, no mínimo, que o seu capital ou a empresa em que investem não sejam confiscados pelo Estado. Esses tribunais, em geral, protegem o direito ao livre mercado e o direito à propriedade, que são essenciais para que haja investimentos externos (VAROL, 2015, p. 1692).

No entanto, como aponta Mark Tushnet (2015, p. 422-423), em regimes autoritários, os governantes podem até querer assumir compromissos credíveis, mas não conseguem passar tanta credibilidade, precisamente porque podem alterar a constituição sempre que quiserem, e os públicos-alvo sabem que eles podem fazê-lo.

Além disso, Cortes Constitucionais também são utilizadas em regimes autoritários para que sejam reduzidas as pressões de organismos internacionais relacionados aos direitos humanos (VAROL, 2015, p. 1692).

Em regimes autoritários, os Tribunais Constitucionais terão certa independência para decidir sobre as mais diversas questões, inclusive para que haja um "verniz" de independência judicial, de separação de poderes, de proteção a direitos e de democracia, como aponta Ozan Varol (2015, p. 1691-1692). Contudo, nesses regimes, dificilmente os Tribunais Constitucionais tomarão decisões que contrariem direitos estruturais ou que afetem diretamente o regime.

Ademais, um regime autoritário pode se utilizar do Tribunal Constitucional para fazer prevalecer as suas preferências, transferindo para este a responsabilidade em relação a decisões polêmicas, que afetam determinadas elites ou que atingem atores internacionais, reduzindo os custos políticos e mitigando o desgaste da sua imagem no plano internacional (VAROL, 2015, p. 1692-1693).

Os líderes autoritários, para maquiarem seus regimes com legitimidade e legalidade, costumam utilizar uma retórica de Estado de Direito, democracia e constitucionalismo para implementar reformas que chamam de democráticas, mas que, em verdade, contêm medidas antidemocráticas ou de restrições democráticas. ${ }^{7}$

\footnotetext{
"For example, Vladimir Putin deployed judicial review to help consolidate his power in Russia. For the purported purpose of creating a unified political space, he authorized federal courts to nullify regional laws inconsistent with the federal constitution. That authorization appears, at least on its surface, to be nothing more than a neutral, straightforward assertion of vertical federal supremacy and is consistent with the models in other federal states, including the United States. According to Putin, the new federal judicial authority to strike down regional laws would thus merely reemphasize 'Russia's commitment to 'legality and the state'.' The Russian federal courts deployed their newfound power with zeal and struck down thousands of regional laws. The elimination of those regional laws allowed Putin to centralize and consolidate his power and reduce the vertical checks on his power by regional governments" (VAROL, 2015, p. 1689).

"To imbue their regimes with the veneer of legitimacy and legality, authoritarians or would-be authoritarians frequently implement democratic reforms and employ rhetoric that invokes the rule of law, democracy, and constitutionalism. This sleight of hand can distract domestic and international audiences who often fail to detect anti-democratic measures through the fog of democracy rhetoric and reforms [...] In addition to democratic reforms, rhetoric that invokes the rule of law, democracy, or constitutionalism is often used to distract audiences from anti-democratic practices. Now-President Erdogan in Turkey, for example, frequently reiterates his grand vision of creating an 'advanced democracy' in Turkey. He also rebuts criticisms levied at controversial government measures either by citing a constitutional or legal basis for the measure or invoking comparative law and pointing to a democratic country (usually in the West) that has implemented the same measure. For example, a set of constitutional amendments that packed the Turkish Constitutional Court in September 2010 were adopted as part of a 'democratization' package intended to increase the involvement of the political branches in judicial appointments and bring the appointments process in line with liberal democracies, such as Germany" (VAROL, 2015, p. 1715-1717).
} 
Assim, não se pode afirmar que Cortes Constitucionais são inerentes a regimes democráticos, nem que buscam sempre implementar valores democráticos. Também não seria possível estabelecer uma relação de necessariedade entre democracia e crescimento da revisão judicial (GINSBURG, 2003, p. 6). Países marcadamente autoritários também tiveram um aumento do poder de revisão judicial.

Como adiante se mostrará, tem ocorrido a expansão da jurisdição constitucional e do poder das Cortes Constitucionais tanto em regimes democráticos quanto autoritários.

\section{Análise comparativa da jurisdição constitucional em regimes democráticos e autoritários: expansão, risco de captura e ataques}

É possível observar um aumento do poder de revisão judicial à medida que a "terceira onda" de democracia (HUNTINGTON, 1994) avançou pelo mundo, tanto nas democracias estabelecidas quanto nas novas democracias. Nesse tocante, há diversos estudos empíricos que relacionam a atuação ativa de Cortes Constitucionais às transições democráticas e ao desenvolvimento de democracias. Aliás, há evidências de que existe uma relação muito forte entre transição democrática, Estado de direito, crescimento econômico, aumento de investimento estrangeiro e qualidade da governança (SANTISO, 2005, p. 117).

Além disso, têm perdido espaço os estudos que tratam da não intervenção judicial e da ideia de soberania do parlamento como necessárias para a democracia (GINSBURG, 2003, p. 2). Mesmo em países como o Reino Unido, é possível notar a expansão da revisão judicial (GINSBURG, 2003, p. 4).

Aliás, a própria ideia de soberania parlamentar como inerente à democracia parece ter sido datada e teve seu contexto, em que havia maior desconfiança em relação aos juízes. Noutros contextos, em que a desconfiança está mais ligada ao Poder Executivo e, muitas vezes, ao próprio Legislativo, a revisão judicial ganha mais espaço.

Num presidencialismo de coalizão, como é o caso do Brasil e de outros países da América Latina, onde as bases governistas são formadas no Congresso Nacional em razão de concessão de cargos de chefia em Ministérios, autarquias e empresas estatais, é comum que exista maior desconfiança em relação aos Poderes eleitos. Em diversos sistemas em que há um presidencialismo de coalização, a revisão judicial tem se mostrado necessária exatamente para coibir a concentração de poder no presidente em detrimento do Parlamento, ou para preservar a aplicação das próprias regras democráticas.

Ademais, em democracias menos maduras e com mais problemas de corrupção política e/ou concentração de poder, diversos autores defendem uma maior atuação do Judiciário para corrigir essas disfuncionalidades democráticas, como adiante se demonstrará.

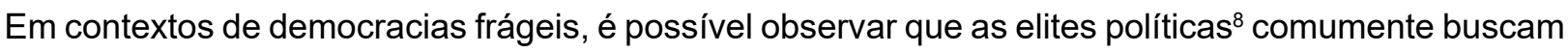
alterar regras constitucionais e infraconstitucionais para, por exemplo, reduzir a competição política, corroer os direitos individuais (PARTLETT, 2015, p. 922-923), aumentar o aporte de recursos estatais para fundos partidários e aprovar medidas de interesse de grupos econômicos que financiam campanhas eleitorais. Em tais situações, fica difícil não concordar que o Judiciário deva ter uma postura mais ativa nas questões de natureza política, sobretudo para corrigir as disfunções na democracia.

A experiência de direito constitucional comparado mostra que a constituição não é sempre um momento para deliberação e reflexão democrática. Em diversos países, a elaboração da constituição e as emendas constitucionais são marcadas pelas manipulações das elites para se consolidarem no poder, implementarem benefícios próprios e, inclusive, prejudicarem direitos fundamentais. ${ }^{9}$

\footnotetext{
B Por "elites políticas", conceito amplamente utilizado nesta tese, pretende-se designar o conjunto de indivíduos que detêm mais poder em determinado grupo, capazes de participar diretamente do processo de tomada de decisão, incluindo a não decisão - segundo a perspectiva neoelitista (PERISSINOTTO, 2009, p. 83-84), de modo que as suas escolhas podem ser impostas à população, ou seja, afetam um grande número de pessoas, ainda que não se deva recair num voluntarismo, já que não se pode desprezar os constrangimentos estruturais que limitam a liberdade de ação das elites políticas (PERISSINOTTO, 2009, p. 97).

9 "Comparative experience of formal constitutionmaking beyond the traditional canon of countries, however, shows that constitution-making is not always a time for democratic selfdeliberation and reflection. Instead, in many countries across the former Soviet Union, Eastern Europe, and South America, formal constitution-making has been characterized by elite manipulation. In many cases, self-interested elites have been able to win elections and then use their resulting control of the constitution-making process to push through formal rules that undermine individual rights and entrench their own power" (PARTLETT, 2015, p. 926).
} 
De outro lado, ainda que as elites políticas possam ter na Corte Constitucional mais uma instância a recorrer quando não conseguem atingir seus objetivos no processo político, isso talvez não seja de todo ruim para a democracia, na medida em que o reconhecimento de que as reivindicações devem ser postuladas dentro das instituições estabelecidas implica, ao menos em princípio, em não tentar buscar o caminho da ruptura democrática. Ao investigar se a revisão judicial seria um fator positivo para o fortalecimento da democracia, os estudos empíricos e comparativos sugerem que a resposta seria afirmativa, pois encorajaria os perdedores no processo legislativo a levar as suas disputas aos tribunais, aumentando a probabilidade de que eles permanecerão leais à ordem constitucional e não tentarão a sua ruptura. ${ }^{10}$

Contudo, em tais casos, que envolvem o arbitramento de conflitos políticos, as Cortes Constitucionais costumam agir com prudência, de modo a não desafiar demasiadamente as elites políticas, ou seja, os Tribunais Constitucionais também buscam a sua autopreservação. Ao analisar se as Cortes Constitucionais têm sido subservientes ao regime ou tem desafiado as autoridades eleitas, Tom Ginsburg, em estudo comparativo entre países asiáticos (Mongólia, Coreia do Norte e Taiwan), afirma que os Tribunais Constitucionais desses países agiram com cautela e prudência, desafiando as autoridades, mas também buscando se assegurar de que as suas decisões seriam faticamente cumpridas. ${ }^{11}$

Isso não quer dizer que as Cortes Constitucionais serão sempre subservientes. Em estudo comparado, Willian Partlett (2015) mostra que, em alguns países, como Índia, Colômbia e África do Sul, os tribunais atuam de forma independente e como "grandes supervisores do exercício do poder político". Segundo ele, "isto sugere que os tribunais podem desempenhar um papel democraticamente legítimo no projeto constitucional" (PARTLETT, 2015, p. 930). Contudo também é preciso ter certo cuidado com a sobrevalorização da atuação de algumas Cortes Constitucionais em estudos comparados. É comum que, para defender determinada tese, pesquisadores exaltem alguns aspectos, fazendo um corte epistemológico, de modo que outras variáveis relevantes sejam negligenciadas. ${ }^{12}$

Nesse aspecto, o próprio Partlett pontua que existe certo otimismo em relação à possibilidade de tribunais melhorarem a Constituição, mas, dentro de uma análise comparativa mais ampla da experiência das Cortes Constitucionais, observa-se que esses três tribunais (da Índia, da Colômbia e da África do Sul) são a exceção, pois, em diversas outras democracias menos desenvolvidas e "países do Sul", ${ }^{13}$ o que mais chama a atenção são problemas familiares de impotência e exploração judicial.

Partlett (2015) afirma, em primeiro lugar, que a experiência comparativa mostra que os tribunais "são frequentemente ignorados em suas tentativas de regular os processos constitucionais"; em segundo, que "um controle de constitucionalidade robusto pode tornar-se uma ferramenta poderosa para novas elites"; e, em terceiro lugar, que os "tribunais podem se tornar instituições guardiãs que ajudam a proteger uma elite particular das maiorias eleitorais concertadas" (PARTLETT, 2015, p. 934). Como exemplos de impotência e exploração judicial, podem ser citados os casos das Cortes Constitucionais da Rússia e da Venezuela.

10 "Is judicial review a good thing for democracy? The case studies presented here have suggested that on balance the answer is yes. Judicial review can deepen the constitutional order and contribute to the consolidation of the democratic system. By providing a nonpartisan forum that issues authoritative pronouncements drawn from the fundamental text, judicial review encourages losers in the legislative process to bring their disputes to court, increasing the likelihood that they will remain loyal to the constitutional order. Judicial review provides an alternative channel for those out of power, be they aspiring Democrats or erstwhile authoritarians" (GINSBURG, 2003, p. 262).

11 "The case studies from Asia have suggested that constitutional courts have for the most part acted with caution and prudence, challenging authorities but securing compliance. With the exception of the Mongolian decision separating the legislature from the government, the institution of judicial review has not been particularly controversial in these three new democracies. There appear to be mechanisms of signal and countersignal over time that moderate the countermajoritarian role of courts, but at the same time, the institutional pressures to expand judicial power help courts continue to push authorities. Over time, incremental decisions can expand the freedom of action available to the court and expand the protection of substantive rights associated with internationally derived notions of the rule of law. In this way, constitutional courts can develop constitutions and deepen democracy at the same time" (GINSBURG, 2003, p. 262-263).

12 Nesse tocante, parece que são selecionados alguns julgamentos das Cortes Constitucionais desses países, a fim de se defender a tese de que existe um Constitucionalismo do Sul, no qual pode se admitir uma maior intervenção judicial para corrigir distorções democráticas.

13 Alguns autores, como Daniel Bonilla Maldonado (2013, p. 21-22), que preconizam a existência de um Constitucionalismo do Sul, com uma nova gramática constitucional. Nesse tocante, tem sido dada como exemplo a atuação de três Cortes Constitucionais, em três diferentes continentes, quais sejam, as Cortes Constitucionais da Colômbia, da África do Sul e da Índia. O autor utiliza como exemplo esses três países que, em casos selecionados, tiveram um papel importante no estabelecimento da democracia ou no combate no autoritarismo, o que, segundo ele, indica que a atuação da Corte Constitucional pode, em alguns casos, melhorar as condições democráticas da instituição desses países. 
A experiência do Tribunal Constitucional russo na década de 1990 é emblemática para mostrar a fraqueza judicial diante do Parlamento e do Governo. Como aponta Partlett, em 1992 e 1993, o Tribunal Constitucional russo, em alguns casos sensíveis, assumiu um papel mais ativo na tentativa de fazer cumprir as regras constitucionais democráticas. Num dos casos, esse Tribunal derrubou um decreto presidencial que buscava unir a polícia interna e a KGB (serviço secreto soviético) em nítida violação à separação de poderes. O Tribunal Constitucional russo limitou o poder presidencial, bem como derrubou extensões inconstitucionais de poder concedidas pelo Parlamento russo. Assim, ao longo do tempo, o Tribunal entrou cada vez mais em choque com o poder presidencial, sendo que o ponto culminante foi essa Corte ter derrubado um decreto do presidente russo que dissolvia a legislatura. Na sequência, como represália, o presidente Boris Yeltsin dissolveu o Tribunal Constitucional e, unilateralmente, impôs uma nova Constituição. Dois anos depois, o Tribunal Constitucional russo foi reaberto, mas com juízes muito mais flexíveis. Portanto, apesar das boas intenções e da tentativa de o Tribunal Constitucional russo fazer o controle dos atos do presidente, no melhor sentido do sistema de freios e contrapesos, ele não conseguiu melhorar as condições democráticas na Rússia governada por Yeltsin (PARTLETT, 2015, p. 935).

O fracasso dos Tribunais Constitucionais em tentativas de melhorar as condições democráticas também pode ser observado em diversos países, como o emblemático caso venezuelano, com problemas que se renovam e se arrastam ao longo do tempo. ${ }^{14} \mathrm{Na}$ Venezuela, o Presidente Nicolás Maduro, depois de uma crise institucional ocorrida em 2017, passou a não mais reconhecer os membros do Tribunal Supremo de Justicia, os quais buscaram exílio em outros países - esses juízes exilados passaram a integrar o que autodenominam de Tribunal Supremo de Justicia de Venezuela en el exilio. ${ }^{15} \mathrm{Em}$ seu lugar, Maduro nomeou juízes que apoiam o seu governo. Ocorre que esse Tribunal Constitucional, na atual composição, tem sido subserviente ao regime de Maduro, dando respaldo aos seus diversos atos antidemocráticos e de abuso do poder presidencial. A título de exemplo, em 31/5/2017, o Tribunal Supremo de Justicia em exercício declarou legítima a possibilidade de Maduro convocar uma nova Assembleia Nacional Constituinte sem referendo (PRESSE, 2017), composta apenas com apoiadores do seu governo ${ }^{16}$ - posteriormente, cedendo a pressões populares, da oposição e de organismos internacionais, a Constituição elaborada por essa Assembleia Constituinte foi submetida a referendo popular e, no escrutínio dos cidadãos, não foi aprovada. ${ }^{17}$ A Secretaria-Geral da Organização dos Estados Americanos (OEA), em 21/8/2018, reconheceu como ilegítimo o Tribunal Supremo de Justiça em exercício na Venezuela (PRESSE, 2018).

Esses exemplos mostram que o Judiciário se revela um poder mais fraco, dependente de capital político e de outras instituições para impor as suas decisões. Caso os Tribunais tentem atuar de forma completamente independente e sem considerar as forças externas que circundam os seus julgamentos, aumentam as chances de que as suas decisões não sejam cumpridas, que elas sejam "contornadas" ou, em situações extremas, que a composição do próprio Tribunal seja dissolvida. ${ }^{18}$

14 "We see a similar failed attempt by a court to check an abusive process of constitutional replacement in Venezuela. This controversy emerged most clearly in the litigation surrounding referendum questions for a new constitutional assembly. A critical question asked whether voters authorized newly elected President Hugo Chavez to personally determine 'the bases of the electoral procedure in which the National Constituent Assembly will be elected'. The court struck this provision down and held that the assembly would not reflect 'the true popular will' if voters were forced to vote on an electoral procedure without knowing what it was. The court issued a follow-up decision clarifying that the National Constituent Assembly was 'bound to the spirit of the constitution in force'. President Chavez easily circumvented both of these decisions, however, by writing the electoral rules in a way that helped ensure that he could dominate the Assembly and later declaring that a National Constituent Assembly dominated by his supporters stood above the existing constitution. Ultimately, therefore, the court failed to block Chavez in his attempt to unilaterally fashion the constitutional rules of the game" (PARTLETT, 2015, p. 936).

15 Os juízes do Tribunal Supremo de Justicia de Venezuela en el exilio se encontram exilados na Colômbia, no Chile, nos Estados Unidos e no Panamá, e se encontram virtualmente uma vez por semana, pela rede mundial de computadores.

16 “[...] desde agosto de 2017, a Assembleia Constituinte da Venezuela, formada exclusivamente por chavistas, assumiu a 'competência para legislar' e 'ditar atos parlamentares em forma de lei'. Essa Assembleia é chamada de 'fraudulenta' pela oposição e não reconhecida por vários países" (PRESSE, 2018).

17 “Venezuela ha dicho 'no' a la reforma constitucional de Hugo Chávez. Por un estrechísimo margen, 50,7\% frente a 49,2\%, los opositores al presidente venezolano le han infligido su primera derrota en las urnas en sus nueve años de Gobierno, rechazando una reforma que le hubiera dado un poder casi ilimitado. Con el $88 \%$ de los votos escrutados, Chávez ha comparecido para reconocer la victoria 'pírrica'de la oposición, pero no ha dado por perdida la guerra. Según él, las reformas han fracasado 'por ahora' y 'siguen vivas', lo que sugiere que podría intentar ponerlas en marcha más adelante" (PEREGIL, 2017).

18 "Courts are weak actors: they neither wield the power of the sword nor the purse. In some cases, the political branches can 'stack' courts with pliant judges or disband them completely. In other cases, courts themselves choose to avoid confrontations with powerful political forces. In both cases, courts are unable to block partisan exploitation of formal constitutional rules. This weakness is particularly acute during times of constitutional replacement when powerful elites - often commanding electoral majorities - seek to fundamentally change the framework of the constitutional order" (PARTLETT, 2015, p. 935). 
Mas a fraqueza judicial evidenciada ao tentar impor as suas decisões não é o único problema que enfrentam as Cortes Constitucionais. O cenário também é preocupante quando os Tribunais Constitucionais são capturados por elites políticas ${ }^{19} \mathrm{e}$ usados para fazer valer determinados interesses, como a concessão de vantagens a determinados atores políticos ou a redução do poder dos partidos de oposição. Esse risco de captura aumenta nas situações em que existe renovação mais acentuada dos membros da Corte Constitucional (quando foram nomeados e aprovados pelo chefe do Executivo e pela legislatura do momento), diante da necessidade de assumirem certos compromissos, ou, ainda, quando existe risco de a Corte Constitucional perder poder, situação em que há maior possibilidade de que esta ceda em casos específicos para manter as suas competências. Assim, a fraqueza judicial é mais alarmante quando Cortes Constitucionais são capturadas pelas elites políticas e utilizadas em detrimento da própria democracia.

O caso da Ucrânia ilustra bem essa questão. O Tribunal Constitucional ucraniano possui, em seu design institucional, poderes significativos para rever as alterações (emendas) constitucionais. Apesar desses poderes formais, o Tribunal tem sido reiteradamente cooptado pelos presidentes do país, como mostra Partlett. A título de exemplo, em 2004, houve uma série de alterações constitucionais aprovadas, logo após a Revolução Laranja, as quais enfraqueceram os poderes do presidente e aumentaram os do Parlamento. Embora tais alterações fossem inconstitucionais, por violarem a separação de poderes, o Tribunal Constitucional não interveio de imediato. Somente seis anos após, sob forte pressão do recémeleito Presidente Viktor Yanukovych, o Tribunal Constitucional ucraniano derrubou essas alterações constitucionais, aumentando efetivamente os poderes do novo presidente e enfraquecendo os poderes dos seus oponentes no parlamento. ${ }^{20}$

Em outros cenários, as Cortes Constitucionais, com membros designados por certas elites políticas, podem atuar apenas para garantir que essa elite sempre se mantenha no poder, e não para melhorar as condições democráticas. Isso é o que aconteceu, por exemplo, na Tailândia, como aponta Partlett (2015, p. 939). O Tribunal Constitucional tailandês atuou por longo tempo para manter uma elite política no poder, bem como bloquear o poder das maiorias eleitorais.

Assim, considerando as democracias mais recentes, é possível observar que, em certas situações, alguns Tribunais Constitucionais, como os da Índia, da Colômbia e da África do Sul, tiveram êxito em enfrentar elites políticas e conseguiram melhorar eficazmente as condições democráticas, ${ }^{21}$ mas essa não é a realidade da maioria das Cortes Constitucionais dos chamados "países do Sul".

Com o mesmo nível institucional de independência e poder, diferentes Tribunais Constitucionais podem ter diferentes desempenhos em relação à manutenção das condições democráticas. Aliás, os diferentes juízes de um mesmo Tribunal Constitucional podem desempenhar diferentes papeis, como defensores ou opositores ao governo, como protetores das minorias ou instrumento da maioria, com uma postura mais

19 "A second problem is when courts are captured by elites and then used as tools for weakening deliberation and negotiation in constitution-making. Courts are extremely prone to be captured and used as the tool of powerful elites seeking to control democratic politics and formal constitutional amendment. In this scenario, powerful political actors use their powers of removal and appointment to create pliant courts that will consistently rule in their favor. As these actors fear a loss of power, they will do anything-including judicial exploitation-because they 'focus on winning at all costs in the immediate future' since 'losing a battle now might mean losing the whole war" (PARTLETT, 2015, p. 937).

20 "This type of 'strategic pressure' is particularly common in countries formerly part of the Soviet Union. In Ukraine, for instance, the constitutional court has significant powers to review constitutional change. Equipped with these review powers, the court has been repeatedly exploited by those with presidential power. The most recent example in Ukraine involves a series of constitutional amendments passed in 2004, in the wake of the Orange Revolution, that weakened the power of the Presidency and strengthened the Parliament. Although the amendments were made in violation of the constitution, the constitutional court took no action. 15 Seven years later, however, the Ukrainian Constitutional Court struck down these 2004 constitutional amendments under heavy pressure from the newly elected President, Viktor Yanukovych. This decision effectively enhanced President Yanukovych's powers and weakened his opponents' powers in the legislature" (PARTLETT, 2015, p. 937-938).

21 "The Indian Supreme Court, the South African Constitutional Court, and the Colombian Constitutional Court have been among the most important and creative courts in the Global South. These Courts are widely seen in Asia, Africa, and Latin America as activist tribunals that have contributed (or attempted to contribute) to the structural transformation of the public and private spheres of their countries. These Courts' jurisprudence has dealt with problems that are important for and frequent in all contemporary liberal democracies. Issues about the interpretation and protection of civil and political rights, for example, have been addressed regularly by these three Courts' case law. Yet these Courts'jurisprudence has also dealt with problems that are specific to or have special importance in the Global South, and the Courts have done so through original and imaginative legal theories and political strategies. Issues related to political violence, poverty, and the consolidation of the rule of law have been an important part of these Courts'jurisprudence. These Courts, for example, have decided cases about the rights of internally displaced people, how to recognize and accommodate adversary religious minorities, the justiciability of social and economic rights in contexts with high levels of poverty, and the limits that Congress has for amending the Constitution in innovative and appealing ways" (MALDONADO, 2013, p. 21-22). 
intervencionista ou menos intervencionista nas ações do governo, com um comportamento mais ou menos ativo na proteção de direitos econômicos, sociais e culturais.

\section{Considerações finais}

É possível observar um aumento do poder de revisão judicial à medida que a "terceira onda" de democracia ${ }^{22}$ avançou pelo mundo, tanto nas democracias estabelecidas quanto nas novas democracias. No entanto a jurisdição constitucional também foi em geral ampliada em regimes autoritários, nem sempre com objetivos legítimos.

Desse modo, análises puramente normativas ou domésticas não conseguem dar respostas satisfatórias para o problema. É preciso considerar a atuação das Cortes Constitucionais frente a elites políticas de mais global, internalizando problematizações além do paradigma jurídico e a partir de análises comparativas, a fim de se analisar como ocorre essa intrincada relação entre Cortes Constitucionais e elites políticas, como aquelas agem e estas reagem a decisões que lhes são contrárias, quais os riscos e as dificuldades da Corte quando enfrenta esses interesses, bem como quais são as respostas das instituições e dos atores políticos.

Considerando a complexidade das questões em que as Cortes Constitucionais intervêm e as grandes dificuldades pragmáticas que enfrentam quando precisam decidir sobre causas de interesse governista ou de elites políticas, a sua real capacidade de melhorar as condições democráticas é muito mais limitada do que a doutrina tradicional de direito constitucional e as teorias constitucionais standard sugerem. Nesse sentido, algumas absolutizações, como "supremocracia" e "ditadura do Judiciário", não se sustentam em todas as situações.

Observa-se que há boas razões para que o governo central e as elites políticas fortaleçam e fomentem o poder de revisão judicial da Corte Constitucional quando esta não se opõe de forma consistente aos seus interesses, sobretudo porque aqueles dispõem de mecanismos políticos suficientes para reduzir o poder desta, descumprir (direta ou indiretamente) as suas decisões ou promover retaliações quando verificam que a Corte não está alinhada aos seus interesses.

Com isso, não quer dizer que Cortes Constitucionais são sempre subservientes. Pelo contrário, diversos Tribunais Constitucionais assumiram um papel importante na redemocratização, bem como se opuseram a elites políticas. No entanto o risco de descumprimento, direto ou indireto, e de retaliações comumente são levados em consideração pelos membros da Corte, o que acaba moldando um padrão de comportamento que se direciona bastante para a prudência ou cautela quando a questão afeta interesses de elites políticas ou do governo central. Enfim, em diversas situações, quando contraria esses interesses, o próprio papel da Corte de manter e aprimorar a ordem democrática passa a ser desafiado.

Portanto, em termos globais, tanto em regimes democráticos como em regimes autoritários, nem sempre há uma correspondência entre aquilo que se pretendia que os Tribunais Constitucionais fizessem e aquilo que, pragmaticamente, são capazes de fazer em prol da democracia.

\section{Referências}

DELMANTO, Roberto. A ditadura do Judiciário. Migalhas, [S.I.],15 mar. 2018. Disponível em: http://www. migalhas.com.br/dePeso/16,MI276327,101048-A+ditadura+do+Judiciario. Acesso em: 26 out. 2019.

GINSBURG, Tom. Courts and new democracies: recent works. Law \& Social Inquiry, Cambridge, v. 37 , n. 3, p. 720-742, Summer 2012.

GINSBURG, Tom. Judicial review in new democracies. New York: Cambridge University Press, 2003.

\footnotetext{
22 Expressão comumente atribuída a Samuel Huntington (1994).
} 
GINSBURG, Tom; MOUSTAFA, Tamir. Introduction: The Functions of Courts in Authoritarian Politics. In: GINSBURG, Tom; MOUSTAFA, Tamir (ed.). Rule by Law: the politics of courts in authoritarian regimes. Cambridge University Press, 2008.

GINSBURG, Tom; SIMPSER, Alberto. Introduction. In: GINSBURG, Tom; SIMPSER, Alberto (ed.). Constitutions in authoritarian regimes. Chicago: Cambridge University Press, 2014.

FRANKLIN, Charles H. Behavioral factors affecting judicial independence. In: BURBANK, Stephen B.; FRIEDMAN, Barry (ed). Judicial independence at the crossroads: an interdisciplinary approach. Thousand Oaks: Sage Publications, 2002. p. 148-159.

HIRSCHL, Ran. The new constitutionalism and the judicialization of pure politics worldwide. Fordham Law Review, New York, v. 75, n. 2, p. 721-753, nov. 2006.

HUNTINGTON, Samuel P. A terceira onda. São Paulo: Ática, 1994.

LEVITSKY, Steven; WAY, Lucan A. Elections without democracy: the rise of competitive authoritarianism. Journal of Democracy, Washington, v. 13, n. 2, p. 51-65, April 2002.

MALDONADO, Daniel Bonilla. Introduction: toward a constitutionalism of the global south. In: MALDONADO, Daniel Bonilla (ed.). Constitutionalism of the global South: the activist tribunals of India, South Africa, and Colombia. New York: Cambridge University Press, 2013. p. 1-37.

PARTLETT, William. Courts and Constitution-Making. Wake Forest Law Review, Winston-Salem, CN, v. 50, p. 921-949, 2015.

PEREGIL, F. Venezuela dice "no" a la constitución de Chávez. El país, Caracas, 3 dez. 2017. Disponível em: https://elpais.com/internacional/2007/12/03/actualidad/1196636401_850215.html. Acesso em: 5 jul. 2019.

PERISSINOTTO, Renato. As elites políticas: questões de teoria e método. Curitiba: IBPEX, 2009.

PRESSE, France. Parlamento venezuelano respalda sentença de tribunal no exílio contra Maduro. G1, [S.I.], 22 ago. 2018. Disponível em: https://g1.globo.com/mundo/noticia/2018/08/22/parlamentovenezuelano-respalda-sentenca-de-tribunal-no-exilio-contra-maduro.ghtml. Acesso em: 16 jul. 2019.

PRESSE, France. Tribunal Supremo venezuelano valida convocação de Constituinte sem referendo. G1, [S.I.], 31 maio 2017. Disponível em: https://g1.globo.com/mundo/noticia/tribunal-supremo-venezuelanovalida-convocacao-de-constituinte-sem-referendo.ghtml. Acesso em: 16 jul. 2019.

SANTISO, Carlos. Economic reform and judicial governance in Brazil: balancing independence with accountability. In: GLOPPEN, Siri; GARGARELLA, Roberto; SKAAR, Elin (org.). Democratization and the judiciary: the Accountability Function of Courts in new democracies. London: Routledge, 2005. p. 117-143.

SWEET, Alec Stone. Governing with judges: constitutional politics in Europe. Oxford: Oxford University Press, 2000.

TUSHNET, Mark. Authoritarian Constitutionalism. Cornell Law Review, New York, v. 100, n. 2, p. 391462, jan. 2015.

VAROL, Ozan O. Stealth authoritarianism. Iowa Law Review, lowa City, v. 100, n. 4, p. 1673-1742, maio 2015.

VILHENA, Oscar. Supremocracia. Revista de Direito do Estado, Rio de Janeiro, ano 3, n. 12, p. 55-75, out./dez. 2008.

Recebido em: 28/10/2019

Aprovado em: 28/04/2020 